\title{
A systematic review of the effect of omega-3 supplements on meibomian gland dysfunction
}

\author{
Mashael Al-Namaeh iD
}

\begin{abstract}
Introduction: Meibomian gland dysfunction (MGD) is the leading cause of dry eye syndrome (DES). Many ocular disorders including DES and blepharitis can be linked to MGD. If we treat MGD, we can treat related diseases easily.

Purpose: This systematic review is intended to determine the efficacy of omega-3 supplementation in MGD patients.

Methods: This systematic review included an electronic search on PubMed and Clinicaltrials.gov to include all randomized clinical trials (RCTs) using omega-3 as a treatment for MGD.

Results: Database search yielded to one RCT and six clinical trials through the MEDLINE of a total of 350 participants for the systematic review and meta-analysis study. The investigated treatment group (omega-3 group) had a positive effect on MGD protection in the invasive sodium fluorescein-tear break up time (NaFl-TBUT) score compared with the placebo group lodd ratio $=8.72,95 \%$ confidence interval: $4.73,16.09 ; p<0.001)$. These data suggest that the odd ratios of the omega-3 group to control group increased the likelihood of the improved stated outcome tear break up time (TBUT) being achieved in the treatment group. No evidence of publication bias was detected in the funnel plot inspection or the Egger's statistical test ( $p=0.2944)$.

Conclusions: A moderate daily dose of omega-3 may be a beneficial therapeutic for MGD. Omega-3 has been beneficial in many diseases, such as heart attack prevention and agerelated macular degeneration, and this systematic review emphasizes its protection against MGD. In addition, this review emphasizes the precision of noninvasive TBUT (NITBUT) compared with invasive NaFl-TBUT which may suggest the importance of NITBUT in the clinic.
\end{abstract}

Keywords: DES, MGD, Omega-3 fatty acids, OSDI, RCTs

Meibomian glands are large sebaceous glands found in the tarsal plates of the upper and lower eyelids. Meibomian glands are termed tarsal glands in Terminologia Anatomica, 1997. Meibomian glands form a single row of about 25 glands in the upper eyelid and 20 glands in the lower eyelid. Meibomian gland function is important to the health and stability of the ocular surface. ${ }^{1}$ Healthy meibomian gland produces sebum, which provides a buffer against the evaporation of the tear film and protects the ocular surface from microbial and environmental threats such as dust and pollen. In many patients, these glands become dysfunctional and cease to produce their secretion.

Meibomian gland dysfunction (MGD) is the leading cause of dry eye symptoms (DES). ${ }^{2}$ Many ocular disorders, including dry eye symptoms, blepharitis, and chalazia can be linked to MGD. ${ }^{3-5}$ MGD's high prevalence and its multiple pathologies suggest that it is a multifactorial disease. ${ }^{6,7}$ If we treat the MGD, we can easily treat the
Ther Adv Ophthalmol

2020, Vol. 12: 1-9

DOI: $10.1177 /$

2515841420952188

(c) The Author(s), 2020. Article reuse guidelines: sagepub.com/journalspermissions
Correspondence to: Mashael Al-Namaeh Assistant Professor, College of Health Sciences, Tusculum University, 60 Shiloh Road, Greeneville, TN 37745 , USA

Mashael.al-namaehI oamk.fi 
related diseases. Omega-3 has been proposed to treat MGD. ${ }^{8-10}$ This systematic review is intended to determine the effectiveness of omega- 3 supplementation on MGD patients.

\section{Methods}

Identification of trials and consideration of data

This meta-analysis study has followed the standards and guidelines of Preferred Reporting Items for Systematic Reviews and MetaAnalyses (PRISMA). Randomized clinical trials (RCTs) that included nontreated groups versus treated groups selected by searching the MEDLINE and Clinicaltrials.gov. The following keywords were used in MEDLINE research: "Randomized Clinical Trials," "Meibomian gland dysfunction," "Omega-3" AND "Adults." For Clinicaltrials.gov database: "Meibomian gland dysfunction," "Omega-3," "Adults" AND "Completed." The selected studies applied no language or other restrictions. Database search was done to include only studies that had a nontreated group versus a treated group. RCTs that did not include placebo groups, and studies that have not being completed or terminated or are still under recruitment, or have not yet been officially approved, have been excluded.

For bias detection, in each eligible study a 7-point predefined quality control was used. The corresponding risk of bias was categorized as low (L), high $(\mathrm{H})$, or unknown (U) for each quality item according to Higgins et al., 2011 \& Liberati et al., 2009. ${ }^{11,12}$ Unknown is used to judge insufficient information if the author does not report the required data. The complete outcome data were judged as "low risk" or "high risk" or "unknown." The "low risk" is used when follow-up percentage of participants lost was lower than 5\% and "high risk" when follow-up loss percentage was more than $20 \%$. For other potential sources of bias, including the bias source, including the funding source reported in each protocol, the term "other bias" has been used.

The overall treatment effect was calculated and the study weight for each study was calculated. Due to the larger sample size of some of the studies, the study weight was calculated and the "true effect" for each study was shown. The larger sample size provides more information than the smaller sample size.
Data extraction. Inclusion criteria. The studies to be included had to

1. Report the effect of omega-3 on dry eye management,

2. Compare omega-3 and placebo drugs,

3. Report at least one of the outcome measures mentioned (TBUT, tear osmolarity, and Ocular Surface Disease Index [OSDI]), and

4. Include a follow-up period of 3 months.

Exclusion criteria. The following criteria have been used to rule out studies from our study:

1. Studies where findings of the interest outcomes have not been published.

2. Studies in which the period of follow-up is longer than 3 months, and no recording of the length of 3 months.

Quality of the comparative studies. Assessment of quality characteristics used the following criteria: (1) random sequence generation; (2) allocation concealment; (3) blinding of participants; (4) blinding of outcome assessment; (5) follow-up $\geqslant 80 \%$; (6) free of selective reporting; and (7) free of other bias. Each study was labeled with the right item either adequate (low risk of bias), unclear (unknown risk of bias), and inadequate (high risk of bias).

\section{Statistical analyses}

The odd ratios (OR) was calculated in each study protocol to distinct the comparison of placebo group to the omega-3 in MGD. OR values more than 1 mean that the investigated treatment has a positive effect in the MGD protection and treatment compared with placebo. The pooled ORs were calculated using a random effect model.

The equivalent $\mathrm{Z}$ test was done to test the null hypothesis for each pooled OR and if $p<0.05$ shows that the comparison between the two groups is statistically significant which leads to null hypothesis rejection.

The study heterogeneity was assessed with the Cochran $\mathrm{Q}$ and $\mathrm{I}^{2}$ statistics. For the heterogeneity qualitative interpretation, the $\mathrm{I}^{2}$ values of at least $50 \%$ were considered to reflect considerable heterogeneity, while values of at least $75 \%$ indicated large heterogeneity, as per the Cochrane Handbook. Publication bias was evaluated using 


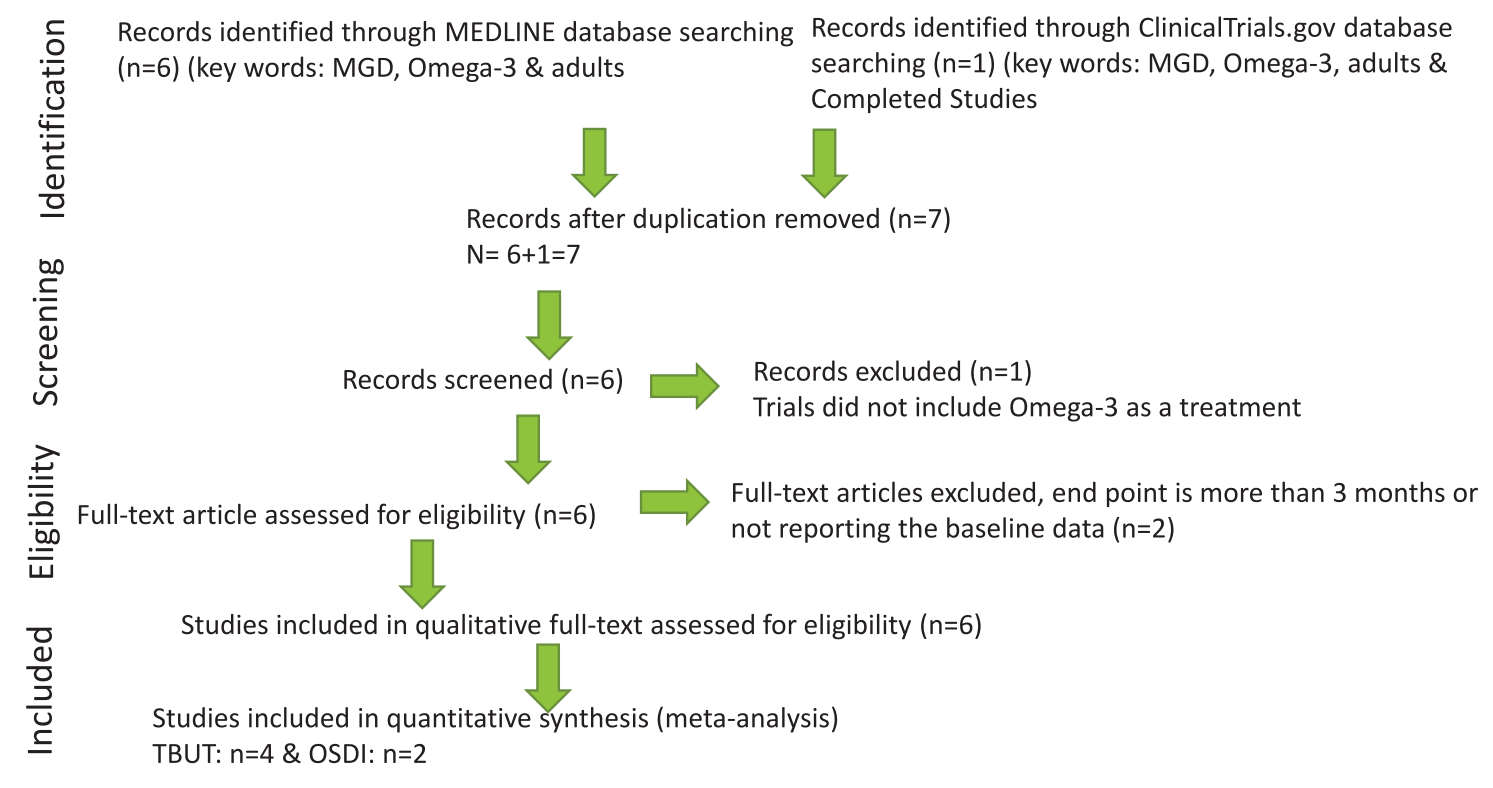

Figure 1. Flowchart presenting the selection of eligible studies.

both the graphical funnel plot and the Egger's statistical test. The Comprehensive MetaAnalysis Version 3 software was used for statistical analysis.

\section{Results}

\section{Selection and characteristics of the study}

MEDLINE and Clinicaltrials.gov database searches resulted in six and one results, respectively. The CENTRAL Register of Controlled Trials database identified no additional RCTs. Duplicate studies were removed, titles and abstracts from the remaining seven studies were evaluated, one study was excluded, and six eligible studies were assessed for the systematic review, and four were assessed for meta-analysis study. Two articles were excluded from the metaanalysis study due to missing data of the primary outcome (TBUT in seconds) or the endpoint was 12 months instead of 90 days. Six studies were retained for qualitative eligibility, ${ }^{13-18}$ and four studies were retained for quantitative eligibility primary outcome (TBUT) ${ }^{13,14,17,18}$ and two studies were retained for secondary outcome (OSDI $^{13,17}$ \& tear osmolarity ${ }^{13,14}$ ). The flowchart presenting the selection of eligible studies is summarized in Figure 1. The Studies that met the inclusion criteria and the characteristics of the included studies are summarized in Table1. All the enclosed studies included placebo group and approved doses of omega- 3 treatment. The approved doses of omega-3 used that are included in the present analysis: Deinema and colleagues ${ }^{13}$ $(1000 \mathrm{mg} /$ day eicosapentaenoic acid (EPA), $500 \mathrm{mg} /$ day docosahexaenoic acid (DHA) for 90 days.), Epitropoulos and colleagues ${ }^{14}(1680 \mathrm{mg}$ of EPA/560 DHA daily for 12 weeks), Korb and colleagues $^{15}$ (combination treatment, $100 \mathrm{mg}$ omega-3 for 3 months).

Malhotra and colleagues ${ }^{17}$ (1.2 g omega- 3 fatty acids for 12 weeks), Macsai ${ }^{16}$ (6 $1000 \mathrm{mg}$ capsules of flaxseed oil daily for 12 months). The studies duration varied from 12 weeks ${ }^{13-15,17,18}$ to 12 months. ${ }^{16}$

\section{Independent studies bias risk}

The risk of bias of the included studies is summarized in Table 2. Random sequence generation was sufficient in all studies except for two. ${ }^{17,18}$ Allocation concealment was adequately reported in three trials, ${ }^{13,15,16}$ two trials were not reported in the article, ${ }^{14,18}$ and one was high. ${ }^{17}$ The blinding of participants and personnel was sufficient in two studies $^{13,16}$ except for four studies. ${ }^{14,19-21}$ The blinding of the outcome assessment was sufficient in three studies except for three, one was unknown, and two were high risk. All of the study protocols reported a follow-up percentage loss between 5\% and $20 \% .{ }^{19,22}$ Selective bias and other bias were not detected in any of the six studies. The study 
Table 1. Characteristics of included studies.

\begin{tabular}{|c|c|c|c|c|c|c|c|c|c|}
\hline Study ID & $\begin{array}{l}\text { Study } \\
\text { type }\end{array}$ & A & $M$ & Intervention dosage & Pt group & $\begin{array}{l}\text { Time } \\
\text { frame }\end{array}$ & $\begin{array}{l}\text { Age } \\
\text { (years) }\end{array}$ & $\begin{array}{l}\text { Actual } \\
\text { enrollment }\end{array}$ & $\begin{array}{l}\text { Primary } \\
\text { outcome }\end{array}$ \\
\hline $\begin{array}{l}\text { Deinema } \\
\text { and } \\
\text { colleagues }^{13}\end{array}$ & । & $\mathrm{R}$ & $\mathrm{D}$ & $\begin{array}{l}\text { Placebo (Olive oil } 1500 \text { mg/ } \\
\text { day) or } \\
\text { Krill Oil ( } 945 \text { mg/day EPA + } 510 \\
\text { mg/day DHA), } \\
\text { Fish oil ( } 1000 \text { mg/day EPA + } 500 \\
\text { mg/day DHA) }\end{array}$ & $\begin{array}{l}\text { Mild to } \\
\text { moderate } \\
\text { DED }\end{array}$ & 90 days & $\geqslant 18$ & 60 & $\begin{array}{l}\text { Mean change in } \\
\text { tear osmolarity } \\
\text { and DED } \\
\text { symptoms } \\
\text { (OSDI) score }\end{array}$ \\
\hline $\begin{array}{l}\text { Epitropoulos } \\
\text { and } \\
\text { colleagues }^{14}\end{array}$ & । & $\mathrm{R}$ & $\mathrm{D}$ & $\begin{array}{l}4 \text { Soft gels total } \\
\text { Treatment Group: } 1680 \mathrm{mg} \text { of } \\
\text { EPA } / 560 \mathrm{mg} \text { of DHA or } \\
\text { control group }=3136 \mathrm{mg} \text { of } \\
\text { linoleic acid daily }\end{array}$ & $\begin{array}{l}\text { DED } \\
\text { MGS STAGE } \\
1 \text { OR } 2\end{array}$ & $\begin{array}{l}12 \\
\text { weeks }\end{array}$ & $\geqslant 18$ & 105 & $\begin{array}{l}\text { Tear osmolarity, } \\
\text { TBUT, OSDI, } \\
\text { Fluorescein } \\
\text { corneal staining, } \\
\text { Schirmer test }\end{array}$ \\
\hline $\begin{array}{l}\text { Korb and } \\
\text { colleagues }^{15}\end{array}$ & I & $\mathrm{R}$ & $\mathrm{D}$ & $\begin{array}{l}\text { Group A = Treatment Group } \\
\text { lipid emulsion eye drops, } \\
\text { omega- } 3 \text { supplements, and lid } \\
\text { hygiene with eyelid wipes } \\
\text { Group B = Apply warm, wet } \\
\text { compresses once daily, } \\
8 \text { minutes per day. }\end{array}$ & MGD & $\begin{array}{l}3 \\
\text { Months }\end{array}$ & $\geqslant 18$ & 26 & $\begin{array}{l}\text { Meibomian } \\
\text { gland } \\
\text { functionality }\end{array}$ \\
\hline Macsai ${ }^{16}$ & । & $\mathrm{R}$ & $\mathrm{D}$ & $\begin{array}{l}\text { Group A: Oral omega- } 3 \text { dietary } \\
\text { supplementation: } \\
\text { two } 1000-\text { mg capsules } 3 \text { times } \\
\text { a day. } \\
\text { Group B = Placebo (olive oil) }\end{array}$ & $\begin{array}{l}\text { Blepharitis } \\
\text { and simple } \\
\text { obstructive } \\
\text { MGD }\end{array}$ & $\begin{array}{l}12 \\
\text { Months }\end{array}$ & $\geqslant 18$ & 38 & $\begin{array}{l}\text { TBUT, meibum } \\
\text { score, and OSDI } \\
\text { score }\end{array}$ \\
\hline $\begin{array}{l}\text { Malhotra } \\
\text { and } \\
\text { colleagues }^{17}\end{array}$ & । & $\mathrm{R}$ & $\mathrm{D}$ & $\begin{array}{l}\text { Both groups received warm } \\
\text { compresses, lid massage, and } \\
\text { artificial tear substitutes. } \\
\text { Treatment group: Oral } \\
\text { supplements of } 1.2 \mathrm{~g} \text { volatile } \\
\text { FAs per day }\end{array}$ & $\begin{array}{l}\text { Moderate } \\
\text { MGD }\end{array}$ & $\begin{array}{l}3 \\
\text { Months }\end{array}$ & $\geqslant 18$ & 60 & $\begin{array}{l}\text { Measure } \\
\text { contrast } \\
\text { sensitivity } \\
\text { under photopic } \\
\text { and scotopic } \\
\text { conditions }\end{array}$ \\
\hline $\begin{array}{l}\text { Olenik and } \\
\text { colleagues }^{18}\end{array}$ & । & $\mathrm{R}$ & $\mathrm{D}$ & $\begin{array}{l}\text { Group A: } \\
\text { Cleaning the lid margins, } \\
\text { artificial tears, a placebo oral } \\
\text { agent. } \\
\text { Group B } \\
\text { Cleaning the lid margins with } \\
\text { neutral baby shampoo and } \\
\text { artificial tears, omega-3 FA oral } \\
\text { supplementation }\end{array}$ & $\begin{array}{l}\text { MGD and } \\
\text { no tear } \\
\text { stability }\end{array}$ & $\begin{array}{l}3 \\
\text { Months }\end{array}$ & $23-85$ & 61 & $\begin{array}{l}\text { TBUT, Schirmer } \\
\text { I test, OSDI, } \\
\text { MG Expression, } \\
\text { Evaluation } \\
\text { of lid margin } \\
\text { inflammation, } \\
\text { interpalpebral } \\
\text { and corneal } \\
\text { staining }\end{array}$ \\
\hline
\end{tabular}

Abbreviations: A, allocation; D, double (participant, investigator); DED, dry eye disease; FA, fatty acid; I, interventional (clinical trial); $M$, masking; MG, meibomian gland; MGD, meibomian gland dysfunction; OSDI: Ocular Surface Disease Index; $P$, prevention; PA, parallel assignment; Pt, patient; $Q$, quadruple (participant, care provided, investigator outcome assessor); $R$, randomized; T, treatment;

TBUT, tear break up time.

protocols are supported financially, partly, or solely by the pharmaceutical companies that produce and market the drug under consideration in each study. Sources of funding were disclosed in all six study protocols to provide enough information to permit fair judgment.

\section{Overall final analyses}

The systematic review of the selected six articles showed that omega- 3 treatment solely or with combination treatment as artificial tears or vitamins improved from baseline in MGD patients. Combination treatment included lid hygiene, artificial tears with nonpreservatives, oral vitamin supplements, and $1000 \mathrm{mg}$ of omega- 3 fatty acids. The meta-analysis primary outcome was invasive NaFl-TBUT improvement from the baseline of the treatment group compared with control group. The secondary outcome was Schirmer I, Ocular Surface Disease Index (OSID), and tear osmolarity test. 
Table 2. Risk of bias summary. Review author's judgments about each risk of bias item for each included study.

\begin{tabular}{|c|c|c|c|c|c|c|}
\hline Study ID & $\begin{array}{l}\text { Deinema } \\
\text { et al., } 2017\end{array}$ & $\begin{array}{l}\text { Epitropoulos } \\
\text { et al., } 2016\end{array}$ & $\begin{array}{l}\text { Korb et al., } \\
2015\end{array}$ & $\begin{array}{l}\text { Macsai } \\
2008\end{array}$ & $\begin{array}{l}\text { Malhotra } \\
\text { et al., } 2015\end{array}$ & $\begin{array}{l}\text { Olenik et al., } \\
2013\end{array}$ \\
\hline $\begin{array}{l}\text { Random Sequence } \\
\text { Generation (Selection Bias) }\end{array}$ & $\mathbf{L}$ & $\mathbf{L}$ & $\mathbf{L}$ & $\mathbf{L}$ & H & U \\
\hline $\begin{array}{l}\text { Allocation Concealment } \\
\text { (Selection Bias) }\end{array}$ & $\mathbf{L}$ & U & $\mathbf{L}$ & L & $\mathbf{H}$ & U \\
\hline $\begin{array}{l}\text { Blinding of Participants and } \\
\text { Personnel (Performance } \\
\text { Bias) }\end{array}$ & $\mathbf{L}$ & U & $\mathbf{H}$ & $\mathbf{L}$ & $\mathbf{H}$ & U \\
\hline $\begin{array}{l}\text { Blinding of Outcome } \\
\text { Assessment (Detection Bias) }\end{array}$ & $\mathbf{L}$ & U & H & $\mathbf{L}$ & H & L \\
\hline $\begin{array}{l}\text { Incomplete Outcome Data } \\
\text { (Attrition Bias) }\end{array}$ & $\mathbf{L}$ & L & L & L & $\mathbf{L}$ & L \\
\hline $\begin{array}{l}\text { Selective Reporting } \\
\text { (Reporting Bias) }\end{array}$ & $\mathbf{L}$ & $\mathbf{L}$ & $\mathbf{L}$ & $\mathbf{L}$ & $\mathbf{L}$ & $\mathbf{L}$ \\
\hline Other Bias & $\mathbf{L}$ & $\mathbf{L}$ & $\mathbf{L}$ & $\mathbf{L}$ & $\mathbf{L}$ & $\mathbf{L}$ \\
\hline
\end{tabular}

$\mathrm{U}=$ Unkown risk of bias, Insufficient information, L= Low risk of bias, $\mathrm{H}=$ High risk of bias, High $=75 \%$ \& Low=25 \%

Patients receiving omega- 3 treated group had significantly better improvement outcome NaFlTBUT compared with patients receiving placebo $(\mathrm{OR}=8.72 ; 95 \%$ CI: 4.73, 16.09; $p<0.001$; Figure 2). Heterogeneity was not statistically significant using the $\mathrm{I}^{2}$ value of $18.60 \%$ and $p=0.383$. In addition, no publication bias was detected using the funnel plot inspection (Supplemental S1-Figure 1) and the Egger's statistical test $(p=0.15)$.

The secondary outcome was Schirmer I test, OSID, and tear osmolarity. For the Schirmer test, Malhotra and colleagues, ${ }^{17}$ Epitropoulos and colleagues, ${ }^{14}$ and Deinema and colleagues $^{13}$ showed that the Schirmer I score improvement are not statistically significant in either group.

For OSID, patients receiving omega-3 had a significant improvement compared with patients receiving placebo, $p<0.005$ (Figure 3). Only two studies included tear osmolarity, and both studies showed a statistically significant improvement in tear osmolarity in the omega-3 group compared with placebo. ${ }^{13,14}$ These data suggest that omega- 3 improves the signs and symptoms of MGD.

\section{Discussion}

This systematic meta-analysis review summarized the studies that evaluated the effect of omega- 3 on MGD. This meta-analysis showed that omega-3 lead to an improvement in MGD signs and symptoms using the Na-TBUT data. Statistical heterogeneity was not found, with a nonstatistically significant heterogeneity between estimates $\left(\mathrm{I}^{2}=18.60 \%, p=0.383\right)$. Finally, the publication bias was not detected using the funnel plot inspection or the Egger's statistical test $(p=0.15)$.

The purpose of pooling the studies together is to show how effective omega-3 in treating MGD and our findings are in line with most of the published clinical trials that omega-3 improve the MGD. One published article showed that there is a decline in the red blood cells and plasma ratios of omega- 6 to omega- 3 in patients taking omega-3 nutritional supplementation relative to the control group and improvements in their overall OSDI score, TBUT, and sebum score. ${ }^{16}$ This is the first evidence of an induced change in the saturation content of fatty acids in meibum as a result of dietary supplementation with omega- 3 fatty acids. ${ }^{16}$ Another publication showed that $1.5 \mathrm{~g}$ of oral omega- 3 fatty acids per day can be beneficial in the treatment of MGD, mainly by enhancing tear stability. ${ }^{18}$ 


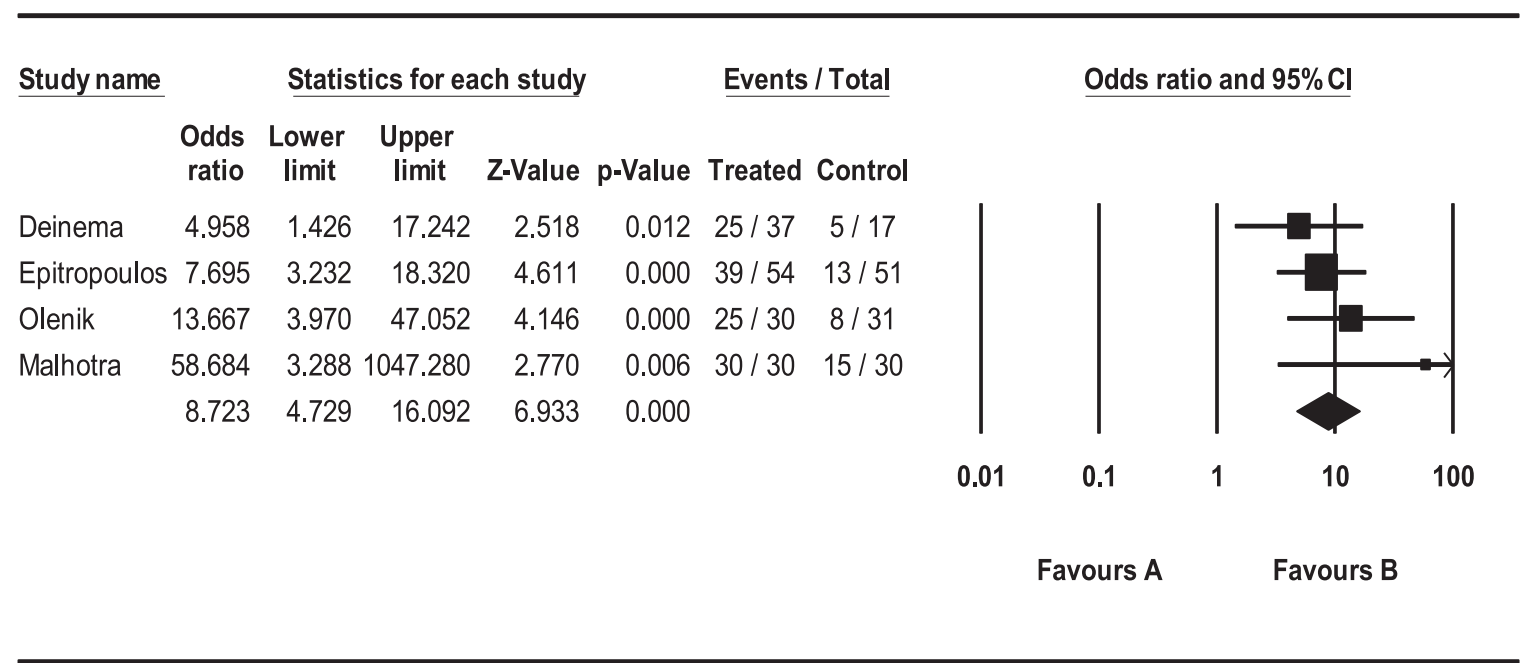

\section{Meta Analysis}

Figure 2. Forrest plot depicting pooled analysis of the $\%$ of TBUT improvement of the treated group versus the control group.

\section{Model Study name}

$\begin{array}{lcccccc} & \begin{array}{c}\text { Odds } \\ \text { ratio }\end{array} & \begin{array}{c}\text { Lower } \\ \text { limit }\end{array} & \begin{array}{c}\text { Upper } \\ \text { limit }\end{array} & \text { Z-Value } & \text { p-Value } \\ \text { Dienema } & 5.021 & 2.747 & 9.178 & 5.244 & 0.000 \\ \text { Malhotra } & 2.185 & 1.228 & 3.885 & 2.660 & 0.008 \\ \text { Fixed } & 3.249 & 2.142 & 4.927 & 5.545 & 0.000\end{array}$

Statistics for each study

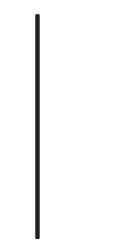

0.01

\section{Odds ratio and $95 \% \mathrm{Cl}$}

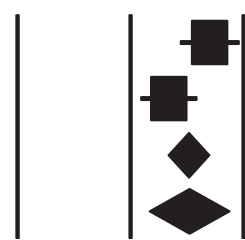

$\begin{array}{llll}0.1 & 1 & 10 & 100\end{array}$

Favours A Favours B

\section{Meta Analysis}

Figure 3. Forrest plot depicting pooled analysis of the \% of OSDI improvement of the treated group versus the control group.

Epitropoulos and colleagues ${ }^{14}$ showed that statistically significant improvements in tear osmolarity, omega-3 index levels, invasive Na-TBUT, MMP-9, and OSDI symptom scores are correlated with oral consumption of re-esterified omega-3 fatty acids. Schirmer test with anesthesia of the treated group versus the placebo group was not statistically significant.
Deinema and colleagues ${ }^{13}$ showed that both forms of long chain omega- 3 in moderate daily dose for 3 months led to lower tear osmolarity and improved tear stability in individuals with dry eye disease. In addition, there was statistically significant improvement in invasive NaFl-TBUT and no change in noninvasive TBUT (NITBUT) between the two groups. Furthermore, Schirmer 
test score was not statistically significant-the use or nonutilization of topical anesthetics was not disclosed.

Malhotra and colleagues ${ }^{17}$ showed that oral supplementation of omega-3 fatty acids considerably enhanced contrast sensitivity in patients with moderate MGD under photopic and mesopic testing conditions. The stability of the tear film significantly improved while there was no impact on aqueous tear production. ${ }^{17}$ In addition, the invasive NaFlTBUT showed statistically significant improvements between the two groups. The Schirmer test score without anesthesia was not significant.

Korb and colleagues ${ }^{15}$ have shown that the combination treatment regimen of lipid emulsion eye drops, eyelid cleansing wipes, and omega-3 vitamin supplements has resulted in significant improvements in the functionality of meibomian gland and dry eye symptoms.

Olenik and colleagues ${ }^{18}$ showed that the treatment group had significantly improved the OSID score, NaFl-TBUT, and Schirmer test without anesthesia in 3 months. This is the only article that showed significant improvements in the Schirmer test without anesthesia in the six studies.

Macsai $^{16}$ was the only study that evaluated the MGD signs and symptoms at 1 year, rather than 3 months. It was the longest study period of the studies assessed here. This study showed that there was an improvement in OSID score and NaFl-TBUT, but no improvement in Schirmer test with anesthesia in 12 months.

This meta-analysis review confirmed some limitations on the interpretation of the results of our study results that need to be acknowledged. One study only showed the results in 12 months and did not show the 3 months results, so it could not be included in the present meta-analysis. In addition, invasive NaFl-TBUT data were used in this review due to the lack of data of NITBUT in the selected RCTs. It has been shown that NITBUT had higher sensitivity and more precision than invasive NaFl-TBUT. ${ }^{23-28}$ It is suggested that future studies should consider noninvasive or other less variable measures for TBUT.

The meta-analysis suggests that omega-3 supplements are indicated. In addition, this systematic review provides enough evidence to show the importance of omega-3 intervention in MGD patients.
Omega-3 has been beneficial in many diseases such as cardiovascular disease, cancer, Alzheimer's disease, dementia, and rheumatoid arthritis. In addition, omega- 3 has been beneficial for eye diseases such as age-related macular degeneration, and this systematic review emphasizes its protection against MGD and DES. Most clinical tests used in clinics to help diagnose MGD are TBUT, Schirmer's test, tear osmolarity, and OSDI. One of the important tests used is TBUT; this review emphasizes the precision of NITBUT compared with invasive NaFl-TBUT which may suggest the importance of NITBUT in clinical practice.

Our study combined the data from the six studies that passed the inclusion criteria; hence, we are confident that our findings are accurate. However, it is important to discuss the meta-analysis limitations, which are as follows: first, the sample size is only 350 subjects, which may represent a small sample size that may suggest a publication bias compared with larger sample size. ${ }^{29}$ However, this highlights the lack of studies in this area. On the other hand, the larger the sample size, the more heterogeneity in selecting participants. ${ }^{30}$ Second, the included studies had the longest follow-up period of 3 months, because most studies had 3 months follow-up. The next step will be to understand the longer-term impact of omega-3, for instance, at 6 and 12 months post-treatment. This concludes that the limited number of studies highlights the lack of research in this field, as well as the need for further potential research to study the short-term effect of omega-3 in dry eyes.

\section{Conclusions}

A moderate daily dose of omega-3 may be beneficial therapeutic for meibomian gland dysfunction.

\section{Acknowledgements}

The author thanks Tusculum University for all the help and support.

\section{Author contributions}

Conceived and designed the literature review: MA. Performed the article assessment: MA. Analyzed the data: MA Wrote the article: MA.

\section{Conflict of interest statement}

The author declared no potential conflicts of interest.

\section{Funding}

The author received no financial support. 


\section{ORCID iD}

Mashael Al-Namaeh (iD https://orcid.org/00000002-5253-1175

\section{Supplemental material}

Supplemental material for this article is available online.

\section{References}

1. Wang J, Call M, Mongan M, et al. Meibomian gland morphogenesis requires developmental eyelid closure and lid fusion. Ocul Surf 2017; 15: 704-712.

2. Nelson JD, Shimazaki J, Benitez-del-Castillo JM, et al. The international workshop on meibomian gland dysfunction: report of the definition and classification subcommittee. Invest Ophthalmol Vis Sci 2011; 52: 1930-1937.

3. Mizoguchi S, Iwanishi H, Arita R, et al. Ocular surface inflammation impairs structure and function of meibomian gland. Exp Eye Res 2017; 163: 78-84.

4. Reyes NJ, Yu C, Mathew R, et al. Neutrophils cause obstruction of eyelid sebaceous glands in inflammatory eye disease in mice. Sci Transl Med 2018; 10: eaas9164.

5. Randon M, Liang H, Abbas R, et al. [A new classification for meibomian gland diseases with in vivo confocal microscopy]. $7 \mathrm{Fr}$ Ophtalmol 2016; 39: 239-247.

6. Schaumberg DA, Nichols JJ, Papas EB, et al. The international workshop on meibomian gland dysfunction: report of the subcommittee on the epidemiology of, and associated risk factors for, MGD. Invest Ophthalmol Vis Sci 2011; 52: 1994-2005.

7. Tomlinson A, Bron AJ, Korb DR, et al. The international workshop on meibomian gland dysfunction: report of the diagnosis subcommittee. Invest Ophthalmol Vis Sci 2011; 52: 2006-2049.

8. Thode AR and Latkany RA. Current and emerging therapeutic strategies for the treatment of meibomian gland dysfunction (MGD). Drugs 2015; 75: 1177-1185.

9. Liu Y, Kam WR and Sullivan DA. Influence of omega 3 and 6 fatty acids on human meibomian gland epithelial cells. Cornea 2016; 35: 1122-1126.

10. Qiao J and Yan X. Emerging treatment options for meibomian gland dysfunction. Clin Ophthalmol 2013; 7: 1797-1803.
11. Higgins JP, Altman DG, Gotzsche PC, et al. The Cochrane Collaboration's tool for assessing risk of bias in randomised trials. BMF 2011; 343: d5928.

12. Liberati A, Altman DG, Tetzlaff J, et al. The PRISMA statement for reporting systematic reviews and meta-analyses of studies that evaluate health care interventions: explanation and elaboration. Ann Intern Med 2009; 151: W65-W94.

13. Deinema LA, Vingrys AJ, Wong CY, et al. A randomized, double-masked, placebo-controlled clinical trial of two forms of omega-3 supplements for treating dry eye disease. Ophthalmology 2017; 124: 43-52.

14. Epitropoulos AT, Donnenfeld ED, Shah ZA, et al. Effect of oral re-esterified omega-3 nutritional supplementation on dry eyes. Cornea 2016; 35 : 1185-1191.

15. Korb DR, Blackie CA, Finnemore VM, et al. Effect of using a combination of lid wipes, eye drops, and omega-3 supplements on meibomian gland functionality in patients with lipid deficient/evaporative dry eye. Cornea 2015; 34 : 407-412.

16. Macsai MS. The role of omega-3 dietary supplementation in blepharitis and meibomian gland dysfunction (an AOS thesis). Trans Am Ophthalmol Soc 2008; 106: 336-356.

17. Malhotra C, Singh S, Chakma P, et al. Effect of oral omega-3 fatty acid supplementation on contrast sensitivity in patients with moderate meibomian gland dysfunction: a prospective placebo-controlled study. Cornea 2015; 34 : 637-643.

18. Olenik A, Jimenez-Alfaro I, Alejandre-Alba $\mathrm{N}$, et al. A randomized, double-masked study to evaluate the effect of omega- 3 fatty acids supplementation in meibomian gland dysfunction. Clin Interv Aging 2013; 8: 1133-1138.

19. Comi G, Martinelli V, Rodegher M, et al. Effect of glatiramer acetate on conversion to clinically definite multiple sclerosis in patients with clinically isolated syndrome (PreCISe study): a randomised, double-blind, placebo-controlled trial. Lancet 2009; 374: 1503-1511.

20. Leist TP, Comi G, Cree BA, et al. Effect of oral cladribine on time to conversion to clinically definite multiple sclerosis in patients with a first demyelinating event (ORACLE MS): a phase 3 randomised trial. Lancet Neurol 2014; 13: 257-267.

21. Freedman MS, Leist TP, Comi G, et al. The efficacy of cladribine tablets in CIS patients retrospectively assigned the diagnosis of 
MS using modern criteria: results from the ORACLE-MS study. Mult Scler F Exp Transl Clin 2017; 3: 1-14.

22. Metz LM, Li DKB, Traboulsee AL, et al. Trial of minocycline in a clinically isolated syndrome of multiple sclerosis. N Engl f Med 2017; 376: 2122-2133.

23. Bergmanson JP and Barbeito R. Clinical assessment of ocular response to a multipurpose contact lens care solution. Ophthalmic Physiol Opt 1995; 15: 535-544.

24. Nichols JJ, Nichols KK, Puent B, et al. Evaluation of tear film interference patterns and measures of tear break-up time. Optom Vis Sci 2002; 79: 363-369.

25. Vidas Pauk S, Petricek I, Jukic T, et al. Noninvasive tear film break-up time assessment using handheld lipid layer examination instrument. Acta Clin Croat 2019; 58: 63-71.
26. Cho P and Douthwaite W. The relation between invasive and noninvasive tear breakup time. Optom Vis Sci 1995; 72: 17-22.

27. Lemp MA and Hamill JR Jr. Factors affecting tear film breakup in normal eyes. Arch Ophthalmol 1973; 89: 103-105.

28. Patel S, Murray D, McKenzie A, et al. Effects of fluorescein on tear breakup time and on tear thinning time. Am $\mathcal{F}$ Optom Physiol Opt 1985; 62: 188-190.

29. Chan AW, Hrobjartsson A, Haahr MT, et al. Empirical evidence for selective reporting of outcomes in randomized trials: comparison of protocols to published articles. $\mathcal{F} A M A$ 2004; 291 : 2457-2465.

30. Yusuf S, Held P, Teo KK, et al. Selection of patients for randomized controlled trials: implications of wide or narrow eligibility criteria. Stat Med 1990; 9: 73-83; discussion 83-86.
Visit SAGE journals online journals.sagepub.com/ home/oed

(3)SAGE journals 